\title{
High School Anti-Bullying Interventions: An Evaluation of Curriculum Approaches and the Method Of Shared Concern in Four Hong Kong International Schools
}

\author{
Gerald Wurf \\ Charles Sturt University, Australia
}

\begin{abstract}
The challenge for high schools to adopt effective measures to reduce bullying has been underscored by international media coverage highlighting the consequences of school bullying. Despite whole-school anti-bullying programs being accepted as the best evidence-based approaches to intervention, research continues to yield ambiguous findings, and only a limited number of studies have been conducted in secondary schools to systematically evaluate the components of this approach. The aim of this study was to investigate the effectiveness of anti-bullying interventions in four international secondary schools in Hong Kong. Schools were randomly assigned to: (a) a whole-school intervention, (b) a curriculum and Shared Concern intervention at Year 7, (c) a Shared Concern intervention at Year 7 and (d) a control school. Year 7 students in the four schools anonymously completed a bullying questionnaire at the beginning $(N=545)$ and end of the school year $(N=549)$. A highly significant main effect for schools was found between pre-test and post-test composite bullying scores $(F=7.70, p<.001)$. Results showed the most significant reductions occurred when a whole-school intervention was used $(F=10.73, p<.001)$. The research provides strong support for use of whole-school preventative/management interventions and the effective components of this approach are discussed.
\end{abstract}

- Keywords: bullying, high school interventions, anti-bullying curriculum, Shared Concern, whole-school approach

For over 3 decades empirical studies have now been conducted in high schools to systematically evaluate anti-bullying interventions using pre-test/post-test, control group designs. Since Olweus' (1993) seminal study in Norway, and Smith's (1999) replication in the United Kingdom, whole-school approaches have been internationally recognised as the best evidence-based method to reduce school bullying. 
Essentially whole-school approaches are seen as consistent with social-ecological perspectives and they are designed to influence factors associated with preventing and managing reported bullying at the school, the classroom and the individual student level (Swearer, Espelage, Vaillancourt, \& Hymel, 2010). According to Rigby, Smith, and Pepler (2004) a whole-school approach generally includes: an antibullying policy, school-wide awareness raising, specific curriculum activities, increased monitoring, and a management plan to deal with reported cases of bullying.

International definitions of student bullying vary; however, it is generally acknowledged that bullying in Western schools involves three essential elements. The first of these elements is that the negative actions are repeated (Rigby, Smith, \& Pepler). A second element used in defining bullying is that the acts occur in the context of a real or perceived power imbalance, with the more powerful student or group targeting those that are less powerful. The final element of bullying is that it causes harm. Although some authors stress cultural differences in bullying definitions (Hazler \& Carney, 2010) cross-cultural support for more universal approaches and definitions has been established by Smith, Cowie, Olfasson, and Liefooghe (2002) and in other international collaboration projects such as the Pacific Rim Research Project (Murray-Harvey, Slee, \& Taki, 2010).

Ericson (2001) identifies physical forms of bullying (hitting, kicking, spitting, pushing, theft), verbal forms (taunting, malicious teasing, name calling, making threats) and psychological forms (spreading rumours, manipulating social relationships, exclusion, extortion and intimidation). In defining cyber-bullying, Hinduja and Patchin (2009) also acknowledge the three elements of repeated actions, a power imbalance and resulting harm (physical, verbal or psychological). Nevertheless, Dooley, Pyzalski and Cross (2009) have noted some distinct differences exist between cyber-bullying and traditional forms of bullying. It has also been noted that in some cultures (e.g., Japan) psychological or indirect forms of bullying are more prevalent than physical forms of bullying (Murray-Harvey, Slee, \& Taki, 2010).

Several researchers have examined teacher and student definitions of bullying and overlap has been found with research definitions. However, Year 7 and Year 9 students are noted to use less comprehensive definitions than teachers use, and students are less likely to refer to social exclusion or a power imbalance when defining bullying (Naylor, Cowie, Cossin, de Bettencourt, \& Lemme, 2006). Vaillancourt et al. (2008) have also noted that students' definitions are far less comprehensive than researcher definitions and that when students are given a definition of bullying, they report lower levels of victimisation.

Despite whole-school approaches being recognised as the best, evidence-based interventions for reducing bullying results from published evaluations of high school interventions have been mixed (Ferguson, San Miguel, Kilburn, \& Sanchez, 2007; Merrell, Gueldner, Ross, \& Isava, 2008). Farrington and Ttofi (2010) have recently completed one of the most robust meta-analyses of published cross-national studies designed to reduce school bullying. Forty-four evaluation studies were included in their analysis and the overall findings showed that on average, school bullying was reduced by $20-23 \%$ following whole-school interventions. Reported victimisation by students was reduced by $17-20 \%$.

A variety of effective program elements was identified by Farrington and Ttofi (2010). These included a whole-school anti-bullying policy; student participation 
in cooperative, group work exercises; the use of videos; improved supervision/monitoring; and the use of school conferences. In addition, the more elements that were used, the more effective the program was at reducing bullying. Farrington and Ttofi concluded that studies that replicated the original Olweus Bullying Prevention Program tended to be the more effective at reducing bullying prevalence rates.

Internationally wide differences have been noted in the prevalence rates of high school bullying. Comparing 35 countries, Due et al. (2009) found adolescent bullying prevalence rates ranged from $5.7 \%$ in Swedish schools to $39.8 \%$ in schools in the Baltic states. These authors propose that the international differences in bullying prevalence rates were related to the country's level of socio-economic inequality. Countries with the largest levels of inequality had the highest prevalence of school bullying. Ng and Tsang (2008) note that in Australia, China, England, Hong Kong, Japan and the United States around $15-25 \%$ of students typically report being bullied at school, sometimes or more often over the last term.

Despite varying levels of bullying, the majority of high school students have reported supporting victims and want to see bullying stopped. Nevertheless, it is now well established that many high school students do not intervene when they witness bullying (Cross et al., 2009). Further, informing others of the bullying declines significantly with age. This is especially true in cases of cyber-bullying (e.g., Dooley, Gradinger, Stroheimer, Cross, \& Speil, 2010). Moreover, when students do inform, Cross and her colleagues found the majority tell their friends $(64 \%)$, their parents/guardians $(57 \%)$ and lastly their teacher/school staff $(46 \%)$. Rigby and Bagshaw (2003) investigated this phenomenon in detail and argued there was a lack of confidence among many secondary students in their teachers' perceived capacity to intervene successfully to stop bullying. They found between the ages of 10 and 14 years, the proportion of Australian students who were actively against or who were unsure about collaborating with teachers to stop bullying doubled to approximately $40 \%$ of students. Cross et al. also report that $45 \%$ of their Australian sample found seeking help from adults resulted in the bullying either staying the same or getting worse.

\section{Anti-Bullying Curriculum Interventions}

Curriculum interventions to address bullying typically involve the collection, dissemination and discussion of survey data, the use of worksheets, whole class discussions, role-plays, cooperative learning activities and the use of supplementary literature/video materials. Class exercises are designed to enable students to define bullying, learn about the nature of bullying (physical, verbal and psycho/social), and identify typical bullying scenarios and unsafe areas within the school. Findings that students are more reluctant to inform teachers of bullying as they move through high school and that most high school bullying remains unreported (at least to teachers) underscores the importance of class level, curriculum activities in educating students about bullying and the mechanisms that are available to stop bullying.

\section{Increased Monitoring and Mediation Using the Method of Shared Concern}

The need for schools to increase supervision and monitoring of students, particularly in areas outside the classroom, has been widely recognised (e.g., Bernard 
\& Milne, 2008; Swearer, Espelage, Vaillancourt, \& Hymel, 2010). Programs for managing reported bullying within schools vary; however, they typically include discipline interventions and/or the use of mediation. Researchers have pointed out multiple problems with the implementation of traditional punitive approaches for managing school bullying, and mediation approaches have generally been favoured (Campbell, 2005; Rigby, 2005). Specific mediation programs that have been developed to assist schools in the nonpunitive management of bullying include Pikas' method of Shared Concern (Duncan, 1996, Pikas, 2002; Rigby, 2005); the use of trained peer mediators (Cowie \& Hutson, 2005; Houlston \& Smith, 2009; Salmivalli, Kaukiainen, \& Voeten, 2005) and restorative justice approaches (Morrison, 2001; Wong, Cheng, Ngan, \& Ma, 2011).

Pikas' method of Shared Concern (Pikas, 1989, 2002) involves a five-phase model of teacher/counsellor intervention. The technique is built around a conflict resolution model incorporating discussions with the students involved in the bullying and importantly, follow-up monitoring. In the first phase, the teacher/counsellor talks individually with the students believed to be involved. The goal of the talk is to elicit a nonpunitive, constructive solution to stop the bullying. In the second phase support is given to the student who was bullied and empathy is shown. The option for mediation is presented and encouraged. In the third phase the teacher/counsellor again meets with the student(s) who bullied to ensure they are still committed to the solution and to check no further incidents of bullying have occurred. In the fourth phase the teacher/counsellor mediator holds a summit meeting with all those involved and a specific agreement is reached to prevent the bullying. The final phase involves follow-up to ensure the bullying has ceased.

The aim of this study is to further investigate effective components of a wholeschool approach using anti-bullying interventions in four international high schools in Hong Kong. International school settings provide a unique advantage in evaluating the effectiveness of universal, whole-school, anti-bullying approaches due the multicultural mix of the student body. An ERIC search returned no results for antibullying interventions in international high school contexts. It was hypothesised that:

1. Interventions that most closely represented a whole-school approach and that included all classes within the high school would be more effective than interventions that only targeted Year 7.

2. The use of a Year 7 only curriculum and mediation intervention (the Shared Concern approach) would reduce bullying levels across the Year 7 cohort.

3. The use of the Shared Concern method of mediation for reported bullying would result in reduced bullying across the Year 7 cohort.

\section{Method}

\section{Participants}

Twenty-one Year 7 classes located in four, international co-educational secondary schools in Hong Kong participated in the study. Students from each school were already allocated into Year 7 classes/houses and completed the questionnaires and curriculum interventions within their classes. In Hong Kong, Year 7 is the first 
year of high school entry. All Year 7 students who were present at their school on the survey days were given the opportunity to take part. A small number of questionnaires $(n=14$ or $1 \%$ ) were rejected from the final analysis due to extensive missing data or highly inconsistent responses that could not be logically coded. From the pre-test, a total of 545 valid questionnaires were included in the analysis. At the 7-month follow-up 549 valid questionnaires were obtained.

\section{Measures}

The secondary school, English version of the Olweus (1991) self-report questionnaire was used to assess the incidence of bullying. Students had not previously completed the questionnaire and it includes a standard definition of bullying. A bullying composite score was used to measure changes in bullying over time and this measure was adopted for the current analysis. The bullying composite score comprises the sum of questionnaire items rating the frequency of being excluded or being indirectly bullied (item 4), the frequency of being bullied (item 5) and the frequency of taking part in bullying others (item 19).

In order to monitor the implementation of the intervention, a brief checklist was devised for teachers involved in the intervention schools. The checklist asked teachers in the intervention schools whether they had delivered the various components of the program, how they had managed reported incidents of bullying and for their personal reactions to the interventions.

\section{Design}

Program effectiveness was evaluated using a factorial, quasi-experimental design incorporating pre/post-test, non-equivalent control groups (Campbell \& Stanley, 1963). The design offers the greatest control of extraneous variables when random assignment of subjects to conditions is not possible. A further advantage of the design is that since existing class arrangements and teachers were used for the intervention, possible threats from reactive arrangements that can occur when students know they are under investigation, were minimised (Gay \& Airasian, 2000).

Bullying in secondary schools is typically found to peak during the early years (e.g., Cross et al., 2009) and only data for Year 7 students was included in this analysis. The four schools that participated in the study had the same administrative structures, funding and each taught the same 'localised' British National Curriculum. This involved adaptations for the Hong Kong/international context. Schools were randomly assigned to one of the following four conditions:

Condition (a) Whole-school intervention for all years;

Condition (b) Curriculum and Shared Concern intervention at Year 7;

Condition (c) Shared Concern intervention only at Year 7;

Condition (d) Control school.

\section{Procedure}

Students anonymously and confidentially completed the questionnaires in class time. Year 7 teachers monitored the administration of the questionnaire using 
standardised instructions under test conditions. The initial pre-test was administered towards the end of the students' first term in Year 7. The post-test was administered at the end of the final term. On each occasion, students were asked to answer the questions about bullying during their current term (i.e., to focus on the last 2/3 months). Those schools implementing the interventions used the second and third term to complete the program. Ethical and school administrative approvals were gained before the research commenced.

In the school assigned to condition (a) the intervention was conducted throughout the whole school. This intervention reflected most clearly a 'whole-school approach' as described within the literature. The intervention commenced with an assembly where summary feedback from the pre-test questionnaires was provided and students were encouraged to become involved in the development of a wholeschool anti-bullying policy. Three lessons, delivered by the class teachers, were then devoted to raising awareness of bullying and school solutions. The lessons were introduced through a video on school bullying and a class discussion. In the second week, students worked in small groups to identify the types of bullying in the school and to discuss strategies to prevent bullying. Bullying scenarios with discussion questions were also prepared. In the third week a worksheet on possible responses to bullying was given to students, and teachers were provided with supplementary role play activities. Existing discipline procedures were utilised to manage bullying, and no formal mediation procedures were implemented.

In the school assigned to condition (b) the above information raising and curriculum activities were replicated except the activities were limited to Year 7 students. Schools in condition (b) and condition (c) adopted the Shared Concern mediation intervention for the management of reported bullying. These schools were given an initial briefing and a package of readings that described the technique. The technique was then role-played with the Year 7 coordinators and two support meetings were held with relevant teachers during the intervention period to review the implementation of the Shared Concern method.

\section{Results}

The data were subjected to several ANOVA procedures in order to investigate the hypothesis that bullying would be reduced significantly following the anti-bullying interventions and that whole-school interventions would be more successful than other/no intervention. Pre-test and post-test class levels of bullying were examined using a two-way repeated measures ANOVA. Class composite bullying scores were used as the dependent variable. The results confirmed a highly significant main effect for all schools $(F=7.70, p<.001)$. The interaction between pre-test and post-test scores was also found to be highly significant $(F=5.23, p<.009)$. Mean pre-test/post-test composite bullying scores for each school are presented in Figure 1.

Student self-reported bullying in condition (a) a whole-school intervention and condition (b) a curriculum and Shared Concern intervention at Year 7 only, was significantly reduced at post-test. In contrast, students reported that overall bullying increased at post-test in the school in condition (c) a Shared Concern only intervention at Year 7. Similarly, student reported bullying increased over the school year 


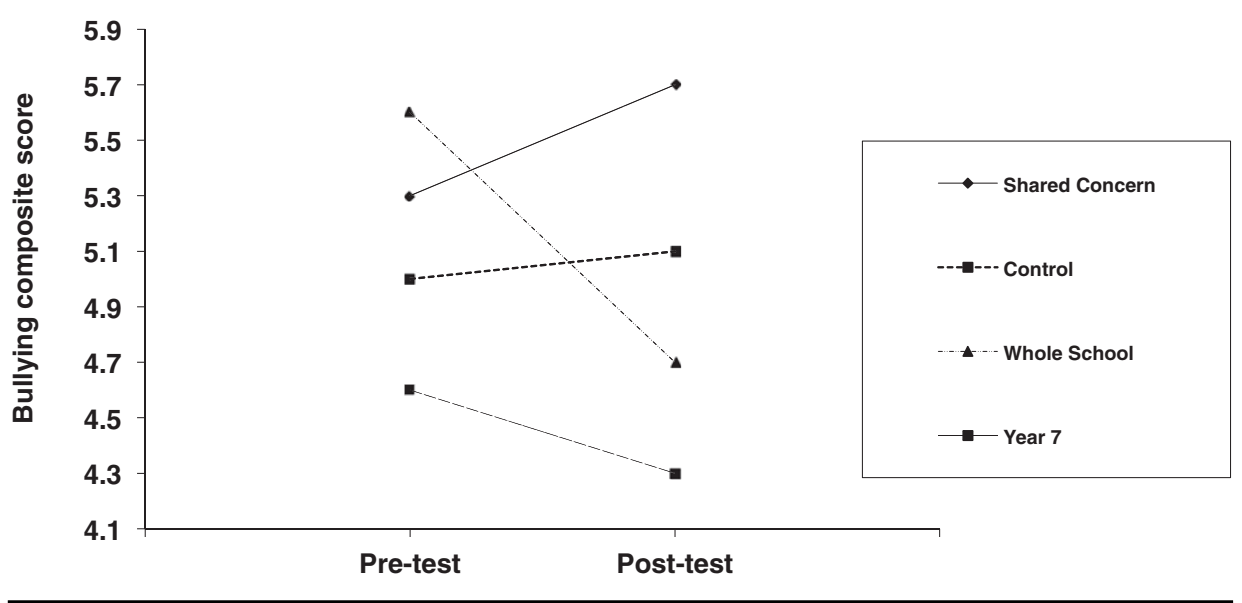

\section{FIGURE 1}

Mean pre-test/post-test bullying scores by type of intervention

in condition (d) the control school. Although these increases were not statistically significant, at post-test students in the Year 7 Shared Concern only intervention and the control school reported the highest levels of overall bullying.

Separate one-way ANOVAs for each school confirmed the above findings. Using the bullying composite score as the dependent variable, a highly significant reduction, $F(1,162)=10.73, p<.001$, in bullying was found for the school in condition (a) whole-school intervention. The reduction equated to a $16 \%$ decline in overall Year 7 bullying. When the answers to the question, 'How often have you been bullied at school this term?' (item 5) was used as the bullying measure, a significant reduction, $F(1,277)=3.44 p<.05$, in bullying was also found in condition (b) a curriculum and Shared Concern intervention at Year 7.

\section{Discussion}

Results from the whole-school intervention provide support for the first hypothesis that school bullying can be reduced significantly through multiple component interventions that form part of a whole-school approach. The greatest reductions in bullying occurred when the components of the whole-school approach were delivered to all classes/years within the high school.

Consistent with hypothesis 2, declines following intervention at the Year 7 level were found; however, the declines were less than when the interventions occurred at all year levels. This may partly relate to the fact that a proportion of bullying in high schools occurs across years. Students in the Hong Kong international schools studied, for example, reported that they were equally likely to be bullied by someone from their own year level as from someone in a higher year.

Hypothesis 3, which predicted that the Shared Concern mediation intervention delivered at the Year 7 level would be effective in reducing overall bullying, was not supported. Overall, reported levels of student bullying increased over the school year in this condition. Nevertheless, teacher feedback from the schools that used 
the Shared Concern method was surprisingly favourable. The finding may be explained by a number of factors. As the majority of bullying traditionally does not come to the attention of school authorities (only $19 \%$ of the students in the Hong Kong international schools studied informed a teacher of bullying) the extent to which interventions at the individual, mediation/counselling level can be effective in reducing overall bullying is extremely limited despite teacher feedback that the technique proved useful in the management of individual episodes of reported bullying.

Similarly, peer mediation programs have not been empirically linked with significant reductions in overall bullying (Farrington \& Ttofi, 2010). For example, Houlston and Smith's (2009) report on the effects of a comprehensive, 1-year peer mediation intervention at an all-girl London secondary school found no reduction in overall bullying levels at the end of Year 7, Year 8 and Year 9.

Findings that mediation interventions have not been associated with reductions in overall bullying may result from a failure to address issues for students who do not report bullying episodes to school authorities. The appropriateness of mediation in cultural contexts where more authoritarian approaches to discipline are traditionally favoured over authoritative approaches has received little attention in the literature. Nevertheless, Wong et al. (2011) have recently reported significant reductions in school bullying following the implementation of a restorative, whole-school intervention in Hong Kong.

Teacher feedback about the curriculum activities that were used was generally very positive. Role-play was the most controversial activity in the curriculum intervention, and teacher opinion was divided on this activity. Half of the teachers' comments were positive and half were unsure of the usefulness of the technique. One teacher was concerned that role-play could provide opportunities for further bullying. This comment reinforces the necessity to provide support and alternatives for teachers who are not familiar with using activities or instructional strategies that are part of curriculum interventions. This support role could be ideally provided by school psychologists/counsellors.

Farrington and Ttofi (2010) concluded that an important component of effective whole-school anti-bullying programs is the use of sanctions/discipline procedures for bullying. Although the use of sanctions/discipline is not necessarily inconsistent with the use of mediation, many studies have reviewed only one or other of the approaches and further research into this area is warranted. Evidence from the United States suggests that 'zero-tolerance' policies may not in fact make schools safer (Tanner, 2009). Tanner notes that zero-tolerance policies have been linked to increased suspensions/expulsions and that the policies are most likely to be applied to visible minority students. He argues that schools that are able to elicit support and commitment for their policies from the whole of the student body (not just the academically achieving students) will be more effective in preventing bullying. Notions of using the least restrictive alternative for school discipline have been advocated for several decades, and the results from the Hong Kong international school study support the use of whole-school programs as an effective intervention at the preventative level.

A possible limitation of the study was that different levels of bullying were evident in each of the schools prior to the commencement of the intervention. The 
success or otherwise of any intervention program may be influenced by the initial levels of bullying in a school. A second limitation is that although the use of anonymous questionnaires has been the mainstay of most evaluation studies, research from Canada suggests that confidential surveys with students providing their names may be just as effective (Chan, Myron, \& Crawshaw, 2005). A further issue in evaluating mediation interventions is that composite school/class levels of bullying may not be a sensitive enough measure to determine if specific techniques such as the method of Shared Concern are effective at the individual level of intervention. The need for schools to work closely with parents in countering bullying has been identified as an effective component in whole-school approaches, and the degree to which this occurred in the international schools was not systematically investigated.

\section{Conclusion}

Consistent with Farrington and Ttofi's (2010) conclusion, this study highlights the fact that schools that include a greater number of successfully evaluated components in their anti-bullying intervention programs can expect the greatest declines in student bullying. The results provide strong support for the use of a whole-school approach for the prevention and management of bullying in high schools. Lessons from this research and the recent comprehensive meta-analysis of bullying interventions over the last 30 years conducted by Farrington and Ttofi provide strong support for schools to:

- adopt a formal, whole-school anti-bullying policy

- use school conferences/assemblies to raise awareness of bullying

- systematically address bullying across all years/classes through anti-bullying curriculum activities

- use anti-bullying videos

- provide teacher training/support in the use and implementation of anti-bullying policies

- improve out of class supervision and monitoring

- actively include parents in anti-bullying programs through training/meetings/ information sessions

- use disciplinary methods/sanctions for bullying

- improve classroom management/classroom rules

- encourage student participation in cooperative, group work exercises.

\section{References}

Bernard M.E., \& Milne M.L. (2008). Safe schools are effective schools: School procedures and practices for responding to students who bully. Melbourne, Australia: Victorian Department of Education and Early Childhood Development.

Campbell D.T., \& Stanley J.C. (1963). Experimental and quasi-experimental designs for research. Chicago, IL: Rand McNally. 
Campbell M.A. (2005). Cyber bullying: An old problem in a new guise? Australian Journal of Guidance and Counselling, 15(1), 68-76.

Chan J.H.F., Myron R., \& Crawshaw M. (2005). The efficacy of non-anonymous measures of bullying. School Psychology International, 26(4), 443-458.

Cowie H., \& Hutson N. (2005). Peer support: A strategy to help bystanders challenge school bullying. Pastoral Care, 23, 40-44.

Cross D., Shaw T., Hearn L., Epstein M., Monks H., Lester L., \& Thomas L. (2009). Australian Covert Bullying Prevalence Study (ACBPS). Perth, Australia: Child Health Promotion Research Centre, Edith Cowan University.

Dooley J.J., Gradinger P., Cross D., Stohmeier D., \& Spiel C. (2010). Cybervictimisation: The association between help seeking and mental health symptoms in adolescents from Australia and Austria. Australian Journal of Guidance and Counselling, 20(2), 194-210.

Dooley J.J., Pyzalski J., \& Cross D. (2009). Cyberbullying and face-to-face bullying: Similarities and differences. Zeitschrift für Psychologie/Journal of Psychology, 217(4), 182-188.

Due P., Merlo J., Harel-Fisch Y., Damsgaard M.T., Holstein B.E., Hetland J., Lynch J. (2009). Socioeconomic inequality in exposure to bullying during adolescence: A comparative, cross-sectional, multilevel study in 35 countries. American Journal of Public Health, 99(5), 907-914.

Duncan A. (1996). The shared concern method of resolving group bullying in schools. Educational Psychology in Practice, 12(2), 94-98.

Ericson N. (2001). Addressing the problem of juvenile bullying. OJJDP Fact Sheet. Washington, DC: Department of Justice, Office of Juvenile Justice and Delinquency Prevention.

Farrington D.P., \& Ttofi M.M. (2010). School-based programs to reduce bullying and victimization: A systematic review for The Campbell Collaboration Crime and Justice Group. Retrieved from http://www.ncjrs.gov/pdffiles1/nij/grants/229377.pdf

Ferguson C.J., San Miguel C.S., Kilburn J.C., \& Sanchez P. (2007). The effectiveness of school-based anti-bullying programs: A meta-analytic review. Criminal Justice Review, 32(4), 401-414.

Gay L.R., \& Airasian P. (2000). Educational research: Competencies for analysis and application (6th ed.). Upper Saddle River, NJ: Merrill.

Hazler R.J., \& Carney J.V. (2010). Cultural variations in characteristics of effective bullying programs. In S.R. Jimerson, S.M. Swearer, \& D.L. Espelage (Eds.)Handbook of bullying in schools: An international perspective (pp. 417-430). New York: Routledge.

Hinduja S., \& Patchin J. W. (2009). Bullying beyond the schoolyard: Preventing and responding to cyberbullying. Thousand Oaks, CA: Corwin Press.

Houlston C., \& Smith P.K. (2009). The impact of a peer counselling scheme to address bullying in an all-girl London secondary school: A short-term longitudinal study. British Journal of Educational Psychology, 79, 69-86.

Merrell K.W., Gueldner B.A., Ross S.W. and Isava D.M. (2008). How effective are school bullying intervention programs? A meta-analysis of intervention research. School Psychology Quarterly, 23(1), 26-42.

Morrison B.E. (2001). The school system: Developing its capacity in the regulation of a civil society. In J. Braithwaite \& H. Strang (Eds.), Restorative justice and civil society (pp. 195-210). Cambridge: Cambridge University Press. 
Murray-Harvey R., Slee P.T., \& Taki M. (2010). Comparative and cross-cultural research on school bullying. In S.R. Jimerson, S.M. Swearer, \& D.L. Espelage (Eds.) Handbook of bullying in schools: An international perspective (pp. 35-48). New York: Routledge.

Naylor P., Cowie H., Cossin F., de Bettencourt R., \& Lemme F. (2006). Teachers' and pupils' definitions of bullying. British Journal of Educational Psychology, 76, 553-576.

Ng J.W.Y., \& Tsang S.K.M. (2008). School bullying and the mental health of junior secondary school students in Hong Kong. Journal of School Violence, 7(2), 3-20.

Olweus D. (1991). Bully/victim problems among school children: Basic facts and effects of a school-based intervention programme. In D. Pepler \& K. Rubin (Eds.), The development and treatment of childhood aggression (pp. 411-446). London: Erlbaum.

Olweus D. (1993). Bullying at school: What we know and what we can do. Oxford: Blackwell.

Pikas A. (1989). The Common Concern Method for the treatment of mobbing. In E. Roland \& E. Munthe (Eds.), Bullying an international perspective (pp. 91-104). London: David Fulton.

Pikas A. (2002). New developments of the Shared Concern method. School Psychology International, 23(3), 307-326.

Rigby K. (2005). The Method of Shared Concern as an intervention technique to address bullying in schools: An overview and appraisal. Australian Journal of Guidance and Counselling, 15, 27-34.

Rigby K., \& Bagshaw D. (2003). Prospects of adolescent students collaborating with teachers in addressing issues of bullying and conflict in schools. Educational Psychology, 32, 535-546.

Rigby K., Smith P.K., \& Pepler D.J. (2004). Working to prevent school bullying: Key issues. In P.K. Smith, D. Pepler, and K. Rigby (Eds.), Bullying in schools: How successful can interventions be? (pp. 1-12). Cambridge: Cambridge University Press.

Salmivalli C., Kaukiainen A., \& Voeten M. (2005). Anti-bullying intervention: Implementation and outcome. British Journal of Educational Psychology, 75, 465-487.

Smith P.K. (1999). England and Wales. In P.K. Smith, Y. Morita, J. Junger-Tas, D. Olweus, R. Catalano, \& P. Slee (Eds.), The nature of school bullying: A crossnational perspective (pp. 67-90). London: Routledge.

Smith P.K., Cowie H., Olafsson R.F., \& Liefooghe A.P.D. (2002). Definitions of bullying: A comparison of terms used and age and gender differences, in a fourteen-country international comparison. Child Development, 73(4), 1119-1133.

Swearer S.M., Espelage D.L., Vaillancourt T., \& Hymel S. (2010). What can be done about school bullying? Linking research to educational practice. Educational Researcher, 39(1), 38-47.

Tanner J. (2009). Making schools safer? The unintended consequences of good intentions. Education Canada, 49(3), 12-15.

Vaillancourt T., McDougall P., Hymel S., Krygsman A., Miller J., Stiver K., \& Davis C. (2008). Bullying: Are researchers and children/youth talking about the same thing? International Journal of Behavioral Development, 32(6), 486-495.

Wong D.S.W., Cheng C.H.K., Ngan R.M.H., \& Ma S.K. (2011) Program effectiveness of a restorative whole-school approach for tackling school bullying in Hong Kong. International Journal of Offender Therapy and Comparative Criminology, 55(6), 846-862. 